\title{
Política radical y autonomismo en Puerto Rico: conflictos de intereses en la formación del Partido Autonomista Puertorriqueño (1887)
}

\author{
Astrid Cubano Iguina \\ Universidad Autónoma de Barcelona
}

\begin{abstract}
"Para los demás hombres cualquier tiempo pasado fue mejor, para mi lo mejor ha estado siempre, y está, en un futuro que nunca llega". Román Baldorioty de Castro, citado por Pilar Barbosa de Rosario: De Baldorioty a Barbosa. Historia del autonomismo puertorriqueño, San Juan, 2." edición, 1974.
\end{abstract}

El trabajo examina las bases sociales del auge autonomista de la década de 1880 en Puerto Rico. Aunque hacendados azucareros afectados por la baja de los precios del azúcar participaron en la fundación del Partido Autonomista Puertorriqueño en 1887, no fueron, como se ha sostenido repetidamente, el grupo propulsor de ese ideal en la forma en que quedó planteado en 1887. El impulso autonomista respondió a la movilización de grupos urbanos indirectamente perjudicados por la misma crisis y estos grupos dotaron al movimiento de un tono radical y democrático. Su propuesta republicana y liberal a ultranza interesaba poco a los hacendados, cuyo principal objetivo en esos años era más bien huir del rigor fiscal a que estaban siendo sometidos por virtud del proceso de modernización legal y hacendística del Estado colonial. Con la esperanza de ejercer mayor influencia a nivel de la administración colonial, optaron por una incómoda alianza con los grupos autonomistas republicanos.

Pocos conceptos se han visto ligados a la trayectoria histórica de Puerto Rico como el del autonomismo. Los orígenes de esta fórmula política en el pasado colonial español han cautivado la atención de estudiosos en diferentes tiempos. No nos son desconocidas las actividades de los líderes autonomistas del siglo XIX ni los principales sucesos en torno a este ideal. Incluso, en tiempos recientes, se han analizado sus bases sociales. ${ }^{\prime}$ Este trabajo intenta profundizar en la comprensión del movi-

I Ver, por ejemplo, Pedreira, Antonio S.: El año terrible del 87, San Juan, México, 1948; Cruz Monclova, Lidio: Historia del año de 1887, Río Piedras, 1970, e Historia de Puerto Rico (siglo XIX), vols. 2 y 3, Río Piedras, 1957; Barbosa de Rosario, Pilar: De Baldorioty a Barbosa. Historia del autonomismo puertorriqueño, San Juan, 2da. edición, 1974; Quintero Rivera, A. G.: Conflictos de clase y política en Puerto Rico, Río Piedras, 1977, págs. 28-31; Negrón Portillo, Mariano: El autonomismo puertorriqueño: su transformación ideológica (1895-1914), Río Piedras, 1981. 
miento autonomista de la década de los 1880, cuando el viejo Partido Liberal Reformista entra en una crisis que culmina con su transformación en el Partido Autonomista Puertorriqueño, fundado en 1887.

No poco tuvo que ver en el auge autonomista de estos años el espaldarazo que dio a este ideal la presencia del catalán Víctor Balaguer en el Ministerio de Ultramar, sensible por razones de interés de su propia región, hacia planteamientos de descentralización política máxima. ${ }^{2}$ Lo mismo podría añadirse de las presiones de los autonomistas de Cuba, reunidos en el Partido Liberal Cubano desde 1878, o de Rafael María de Labra hacia los liberales puertorriqueños para persuadirles de abandonar el asimilismo (que buscaba la igualdad de derechos entre habitantes coloniales y metropolitanos) y abrazar el nuevo ideal de la autonomía dentro de la nacionalidad española. ${ }^{3}$ Pero la alternativa autonomista generó debates dentro del propio grupo autonomista de Puerto Rico. Primero surgió una propuesta para la reforma del viejo Partido Liberal Reformista, conocida como el Plan de Ponce, una enumeración de principios básicos redactada en esa ciudad sureña en noviembre de 1886 por el comité liberal que encabezaba Román Baldorioty de Castro. A continuación, el grupo autonomista de San Juan modificó algunos aspectos esenciales del Plan de Ponce antes de que éste se convirtiese en programa del nuevo Partido Autonomista Puertorriqueño. A partir de entonces, sucesivas divisiones en torno a cuánta autonomía se deseaba o qué áreas eran prioritarias resquebrajaron el proyecto.

La innegable vinculación del brote autonomista de la década de los 1880 con la crisis económica resultante de la caída de los precios del azúcar en el mercado internacional, ${ }^{4}$ ha llevado a algunos estudiosos a pensar que los plantadores azucareros fueron la base social primordial de ese movimiento autonomista. En este trabajo propongo una versión más matizada de los hechos y una leve, pero indispensable revisión de la interpretación del nacimiento de un movimiento tan auténticamente liberal como fue el autonomismo creador del Plan de Ponce de 1886 e inspirado por Baldorioty de Castro. Creo que, sin estar desvinculado del sector azucarero de la colonia, el dinamismo autonomista de los 80 tuvo otros

2 Ver Castro Arroyo, M." de los Angeles: "Introducción" al Plan de Ponce para la reorganización del partido liberal de la provincia, San Juan, 1991, pág. 8.

3 Barbosa de Rosario, De Baldorioty a Barbosa..., págs. 48-49.

4 Para precios del azúcar ver United States Cuban Sugar Council, Sugar Facts and Figures, Nueva York, 1948, pág. 67. 
sectores generadores que no han sido identificados con claridad. Pienso, además, que el impulso autonomista entre muchos hacendados azucareros fue más que nada una reacción frente al fortalecimiento y modernización de la estructura fiscal del Estado colonial. Por último, creo que la importancia de aclarar este matiz está en que contribuye a insertar la política puertorriqueña de esos años en el contexto de las economías exportadoras latinoamericanas, por virtud de la común vinculación al mercado internacional, sin que la particular situación de dominio político colonial español sea un obstáculo fundamental en este tipo de análisis.

\section{Autonomismo y crisis azucarera}

La idea de la relación de causa y efecto entre la crisis económica de mediados de la década de los 1880 y la fundación del Partido Autonomista Puertorriqueño no es nueva. El estudio de Félix Mejías, De la crisis del 86 al año terrible del 87 demostró que algunos de los participantes en la Asamblea de Aibonito (agosto de 1886), una reunión de terratenientes y comerciantes afectados por la crisis para dilucidar soluciones y proyectar reformas, poco después formaron parte de la Asamblea de Ponce (marzo de 1887) en la que se fundó el Partido Autonomista. ${ }^{5}$

Un breve ensayo de Fernando Picó también conecta el descontento que nutrió al autonomismo de los 80 con la crisis de la economía azucarera basada en haciendas tradicionales productoras de azúcar crudo ("moscabado"), que presumiblemente fueron las principales víctimas de la caída de los precios del azúcar por su incapacidad para producir competitivamente. ${ }^{6}$ En este sentido, el autonomismo puertorriqueño se ajustaría al modelo cubano con su ánimo expansionista azucarero y su búsqueda de un régimen arancelario más libre que facilitase la exportación de azúcar a los Estados Unidos, aunque también se mostraba deseoso de subvención estatal o, al menos, crédito agrícola mediante apoyo del gobierno colonial. ${ }^{7}$ Igualmente nota Picó la reconocida necesidad de reducir gas-

5 Mejías, Félix: De la crisis del 86 al año terrible del 87, Río Piedras, 1972.

6 Picó, Fernando, s.j.: "Perspectivas de la investigación histórica sobre el autonomismo en Puerto Rico a fines del siglo 19", Revista Juridica de la Universidad de Puerto Rico, LVI, 2-3, 1987, págs. 515-522.

7 Le Riverend, Julio: Historia económica de Cuba, La Habana, 1985, pág. 537. Ver también, Despatches from United States Consuls in Havana, vol. 80, Despatch no. 724, Aug. 8, 1878. 
tos del Tesoro colonial mediante la colocación de criollos en los cargos públicos. Esto representaba un ahorro ya que los criollos estaban dispuestos a reducir el número de empleados públicos y realizar una administración más eficiente.

En primer lugar, conviene aclarar que la caída de los precios del azúcar y la consecuente crisis de la hacienda tradicional productora de moscabado provocó respuestas de índole muy variada y creó subgrupos dentro del sector azucarero. No todos los mecanismos de adaptación a la crisis se tradujeron en un comportamiento progresista y liberal en lo económico, y no todos aglutinaron intereses afines al resurgir autonomista, sin negar el progresismo azucarero que motivaba a una destacada élite de plantadores autonomistas. Sólo en algunos puntos de la franja costera puertorriqueña la crisis estimuló a la búsqueda de una producción más eficiente mediante la modernización tecnológica. Allí las nuevas centrales azucareras comenzaron a aparecer en el paisaje costero y dieron pie a un episodio de la historia económica de Puerto Rico repleto de aventuras empresariales y gran dinamismo innovador. ${ }^{8}$ Muchos hacendados optaron por cerrar su casa de máquinas y ser colonos de una central cercana, lo que les daba acceso a un potente molino y una tecnología de procesamiento de otra forma inalcanzable. Aunque en forma muy localizada, es decir, válida para ciertos puntos específicos del litoral, la economía azucarera se encontraba en una fase expansiva.

Sin embargo, el hecho ineludible es que el crecimiento de la economía azucarera en Puerto Rico se había detenido, lo que en años como 1884 y 1886 dejaba las exportaciones de azúcar en niveles muy bajos, declive que se confirmará con la notoria caída de los primeros años de la década de $1890 .{ }^{9}$ Se hizo frecuente la reversión a pastos de las fincas de cañas menos rentables, y el aprovechamiento de las restantes mediando cuidadosos mecanismos de reducción de costos: contratación de menor número de braceros y disminución de su salario relativo (resultado no planificado, pero aceptado y apoyado, de la devaluación moneta-

8 Ver, por ejemplo, los trabajos de Ramos Mattei, Andrés: La hacienda azucarera. Su crecimiento y crisis en Puerto Rico (siglo XIX), San Juan, 1981 y "El surgimiento del complejo económico social de la central azucarera en Puerto Rico: 1873-1898" en La sociedad del azúcar:1870-1910, Río Piedras, 1988, págs. 25-52; Martínez Vergne, Teresita: "An Experiment in Capitalism: Central San Vicente, 1873-1892" Tesis, University of Texas, Austin, 1984; Mintz, Sidney W.: Sweetness and Power. The Place of Sugar in Modern History, New York, 1985. pág. 291.

9 Colón, E.D.: Datos sobre la agrícultura de Puerto Rico antes de 1898, San Juan, 1930, 
ria), producción controlada y limitada a los recursos del hacendado sin incurrir en transacciones a crédito, especialización en azúcares moscabados de calidad superior y con mercados limitados pero seguros y aprovechamiento de las mieles en la industria del ron. Además, el ingreso familiar del hacendado se complementaba con la cría de ganado, el cultivo de frutos de consumo local o de tabaco para exportación y, en el caso de aquéllos que también eran propietarios de firmas mercantiles, con la inversión en el prometedor negocio del café mediante la financiación de caficultores del interior. ${ }^{10}$ Aunque los expertos en economía liberal (por ejemplo, los redactores de la Revista de agricultura, industria y comercio), " defensores acérrimos de la modernización azucarera, interpretaban la situación de adaptación a la crisis como una catástrofe económica, lo cierto es que había más segmentos estables y facciones de opinión política conservadora dentro del grupo azucarero de lo que los historiadores suelen admitir.

Así, el ordenamiento de prioridades dentro del grupo azucarero era muy variado. Mientras algunos se mostraban impacientes por obtener mayor acceso al financiamiento extranjero mediante una garantía estatal y libertad de comercio con el principal mercado comprador (Estados Unidos), otros se oponían a crear una deuda pública externa para subvencionar el azúcar y a sustituir las rentas aduaneras que dejaba el comercio con los Estados Unidos por otro tipo de contribución al erario público. Se veía con desconfianza involucrarse en las redes del crédito internacional, ya que esto, no sólo acarrearía un aumento general de los impuestos para beneficio de los plantadores más fuertes, sino que podía eventualmente ocasionar el traspaso de las valiosas vegas costeras de los más débiles a los acreedores extranjeros. ${ }^{12}$ Tampoco se descartaba la op-

10 Cubano, A.: "Sugar Trade and Economic Elites in Puerto Rico: Response to the Sugar Crisis in the Arecibo Region, 1878-1898" Historia y Sociedad, 2, 1989, págs. 70-89. Mi investigación de la región de Arecibo ofrece evidencia de la aplicación de los mecanismos mencionados, algunos de los cuales se confirman en Ramos Mattei, Andrés: "Las haciendas del litoral sur: 18801910" en La sociedad del azúcar.., págs. 55-84. En Mayagüez en 1886 las 18 haciendas azucareras de la municipalidad habían revertido parcialmente en pastizales y sus propietarios se dedicaban a la venta de ganado o de frutos menores. Archivo Histórico Nacional, Madrid, Ultramar, 1182. exp. 5 y $8,1886$.

11 Ver por ejemplo, Revista de agricultura, industria y comercio, abril y diciembre de 1886.

12 Para la discusión sobre el banco agrícola ver Domínguez, José de Jesús: La autonomía administrativa en Puerto Rico, Mayagüez., 1887, págs. 58-63; para evidencia del traspaso de centrales declaradas en bancarrota a sus acreedores extranjeros ver Ramos Mattei, La sociedad del azúcar..., págs. 36-47; ver un primer esbozo de este argumento en Ramos Mattei, "New Trends in Puerto Rican History" Newsletter: Conference on Latin American History, v. 20, 1, April 1984. 
ción de luchar por obtener acceso protegido en el mercado peninsular, antes que ampliar contratos con los refinadores norteamericanos que tan bajo cotizaban su producto. ${ }^{13}$

Muchos hacendados de moscabado habían comenzado a sentirse compensados con la devaluación internacional de la moneda que circulaba en la isla, que se hacía evidente desde comienzos de la década de los 1880. ${ }^{14}$ Aunque la devaluación encarecía las importaciones de maquinaria (haciendo más difícil la modernización de los métodos de producción azucarera), la política de otorgar a la moneda, a efectos de la circulación interna, un valor superior al del mercado internacional, abarataba los jornales de los braceros, lo mismo que los pagos al Estado, y hacía a los productores más competitivos en el exterior. El encarecimiento de los alimentos importados resultante de las imposiciones arancelarias y de la propia devaluación, se compensaba con el alza en el negocio de la producción de frutos de consumo local, en el cual los propios hacendados participaban, directa o indirectamente, como comerciantes financiadores de los agricultores locales.

Sin embargo, demasiadas cláusulas de la declaración de principios básicos y prioritarios sobre la que originalmente se planteó la reorganización del Partido Liberal Reformista en 1886 (el Plan de Ponce) contradicen lo que tendría que haber sido el proyecto de la mayoría de los hacendados azucareros. ${ }^{15}$ En el Plan de Ponce se expresaba un grupo republicano en política, consistente y doctrinariamente liberal en lo político y lo económico: librecambista, lo mismo que defensor de la libertad bancaria y de la adopción del patrón oro en el sistema monetario nacional, lo que si bien facilitaba la proyectada apertura al crédito externo, también habría resultado en una revisión de los salarios devaluados respecto al exterior. Proponía, igualmente, el sufragio universal masculino. Esto último habría otorgado un arma poderosa a los grupos jornaleros y artesanos, que para 1889 ya habrán experimentado el encarecimiento de su costo de vida en un $25 \%$, sin que hubiese ocurrido el correspondiente ajuste en los salarios. ${ }^{16}$ No sorprende, pues, que los gremios artesa-

13 Revista de Agricultura industria y comercio, diciembre de 1886, pág. 205; Boletín Mercantil, 13-15 de agosto de 1875; 11-16 de abril de 1875; Cruz Monclova, Lidio: Historia de Puerto Rico, vol. 2, págs. 497-498; Boletín Histórico de Puerto Rico, San Juan, 1914-1927, vol. XI, pág. 373.

14 Ver Boletín Mercantil, 3 de mayo de 1895.

15 Plan de Ponce para la reorganización del Partido Liberal de la Provincia, San Juan, 1991.

16 Boletín Mercantil, 26 de junio de 1889; 17 de julio de 1889. 
nales de San Juan y Juana Díaz enviaran telegramas de felicitación y adhesión a Baldorioty de Castro durante la Asamblea de Ponce, donde se discutía la aprobación del Plan como base de un nuevo partido liberal y autonomista. 17

Tampoco sorprenden las dudas que suscitó el Plan de Ponce entre los autonomistas cubanos que intentaban establecer una alianza con los autonomistas de Puerto Rico. Los diputados autonomistas cubanos declinaron la invitación que les había hecho Baldorioty de Castro para asistir a la Asamblea de Ponce, ya que creían que el Plan de Ponce "difiere, no poco, de nuestro programa" y como era sabido que tenía el respaldo de los comités liberales de varios pueblos de la pequeña Antilla (aunque no de todos), era preferible, antes de establecer relaciones políticas entre ambas islas, esperar a conocer los resultados de dicha Asamblea para saber si los principios adoptados serían compatibles con los del autonomismo cubano. ${ }^{18}$

El Comité Autonomista de la ciudad de San Juan aportó las enmiendas necesarias al Plan de Ponce, para lograr la fortaleza que les otorgaba la unión con el poderoso movimiento cubano. Los delegados de la Capital en la Asamblea de Ponce lograron dirigir el foco hacia las cuestiones menos doctrinarias y precisar, entre otras cosas, que se exigía el derecho de las colonias a votar y formar sus propios presupuestos, impuestos, aranceles y tratados de comercio, a la vez que reemplazaron la petición del sufragio universal por la de la ley electoral que regía en la Península, donde no estaba vigente ese derecho. ${ }^{19}$ Igualmente fue preciso modificar la orientación republicana del Plan de Ponce antes de ser incorporado al programa del nuevo Partido Autonomista. El partido admitiría miembros comprometidos con las ideas monárquicas, lo que de un golpe neutralizaba el radicalismo del Plan original.

La escisión entre liberales a ultranza y moderados dentro del grupo fundador no carece de significado y creo que merece atención cuidadosa. Se hace pertinente la pregunta de quiénes, o qué grupos sociales eran 1991.

17 Acta de la Asamblea Constituyente del Partido Autonomista Puertorriqueño, San Juan,

18 Cruz Monclova, Lidio: Baldorioty de Castro, San Juan, 1973, pág. 137; Barbosa de Rosario, De Baldorioty a Barbosa..., págs. 53-63.

19 Acta de la Asamblea Constituyente del Partido Autonomista Puertorriqueño...; Martínez Cuadrado, Miguel: La burguesía conservadora (1874-1930), Historia de España Alfaguara IV, Madrid, 1973, pág. 23. 
capaces de proponer un texto como el del Plan de Ponce, ya que definir el autonomismo del 87 sólo en términos de intereses azucareros es claramente insuficiente, como también lo es la explicación más tradicional que percibe la división San Juan-Ponce (norte-sur) como la clave de la rivalidad. 20

\section{Importadores y otros grupos urbanos frente al autonomismo}

La crisis azucarera y monetaria afectó más severamente a grupos urbanos, consumidores de alimentos importados, y a comerciantes importadores con menor capacidad de adaptación que los plantadores. A la nuevas necesidades percibidas ante la crisis del azúcar que contraía la economía urbana, se sumaron los antiguas reivindicaciones de maestros, periodistas y otros profesionales residentes de los centros urbanos, y carentes de acceso al poder político y al cargo público. Su movilización política en el asfixiante contexto del estancamiento de la economía de exportación de azúcar, en años en que la del café aún no se levantaba decisivamente, encontró expresión no sólo en el Plan de Ponce de 1886, sino que adquirió tonos de intenso radicalismo. Creo que obtendríamos una visión más clara de este movimiento si lo relacionamos con el radicalismo que floreció en más de un país latinoamericano a fines de siglo XIX como resultado de las caídas de precios de diversos productos de exportación, resultado a su vez, de la sobreproducción mundial y los ciclos depresivos que azotaron el mercado internacional a partir de 1873. Grupos urbanos en Puerto Rico, lo mismo que en otros países exportadores, agobiados por políticas de devaluación monetaria destinadas a maximizar las ganancias del sector exportador, demandaron una apertura del sistema político que les otorgase algún poder decisorio y acceso a los cargos públicos. Constituyeron una precoz respuesta al liberalismo positivista y autoritario que cuajó en la segunda mitad del siglo XIX y, sin cuestionar lo más básico del proyecto oligárquico, plantearon un reto democratizante de cierta envergadura. ${ }^{21}$

20 Ver por ejemplo, Cruz Monclova, Baldorioty..

21 Hale, Charles: "Political and Social Ideas in Latin America, 1870-1930" en Leslie Bethell, ed.: The Cambridge History of Latin America IV, Cambridge, 1986, págs. 367-442; Para el caso de Argentina ver Rock, David: Argentina, 15/6-1982, Londres, 1986, págs. 152-161 y $183-186$. 
Una de las facciones más radicales del autonomismo puertorriqueño de los 1880, y una de las que más ha cautivado la atención de historiadores por su valiente enfrentamiento al poder colonial, fue la que se organizó en sociedades secretas para promover la economía criolla y boicotear las casas comerciales peninsulares de la isla. El conflicto se ha presentado invariablemente como la culminación de la larga lucha de los puertorriqueños contra la dominación colonial, y se ha dejado a un lado su estudio como fenómeno político radical. ${ }^{22} \mathrm{El}$ movimiento del boicot representó un auge insólito de la política radical en la isla.

El radicalismo en Puerto Rico, lo mismo que en otros países latinoamericanos, era la expresión de grupos urbanos en demanda de poder político y con un equipo teórico fundamentalmente liberal. Pero a diferencia de otros países, en Puerto Rico el grupo que dominaba la vida política y buena parte de la económica, especialmente el comercio, era el representante de la opresión colonial, es decir, era de origen peninsular. Así, el choque adquirió visos de conflicto étnico entre criollos y peninsulares. En una sociedad colonial donde las normas y prácticas de reclutamiento al empleo público y al gran comercio favorecían a la minoría procedente de la Metrópoli, se creaba necesariamente un grupo dominante que por etnia y cultura se distinguía con claridad del resto de la población. La distinción se hacía todavía más marcada en una sociedad que había sido esclavista y donde la reivindicación de lo criollo se confundía con frecuencia con la reivindicación de grupos medios (principalmente maestros y otros profesionales) de origen racial mixto.

En 1887 se estableció, pues, un frente de reivindicación urbano y criollo encabezado por maestros, periodistas y otros profesionales, que resentían la marginación a que muchos de ellos se veían sometidos por el régimen español. Las oportunidades de mejoramiento individual en esos campos estaban limitadas en parte por los estrechos recursos que asignaba el régimen a áreas (como la educación) que no tenían prioridad de acuerdo a los criterios vigentes, $y$ en parte, por la concurrencia de inmigrantes peninsulares. Los criterios de selección estaban claros; se favorecía a peninsulares y a criollos adictos al sistema que no fuesen un obstáculo a las directrices políticas establecidas. De esta forma, la oposición autonomista sirvió de punto de arranque para proponer cambios al

22 Ver por ejemplo, Cruz Monclova, Historia del año de 1887...; Pedreira, Antonio S.: El año terrible del 87. 
orden de prioridades en el gasto público y en las prácticas de reclutamiento para el servicio al Estado.

Los casos paradigmáticos los proporciona el propio liderato autonomista. Hombres como Román Baldorioty de Castro, presidente del Comité propulsor del Plan de Ponce y convencido autonomista republicano, Ramón Marín y Francisco Gonzalo Marín, leales seguidores de Baldorioty, y José Celso Barbosa, joven médico de color, hijo de un albañil y comprometido ya en 1887 con posturas radicales, son representativos del grupo profesional criollo. La militancia de los dos primeros en el reformismo liberal de la década de los 1870 les había ganado la hostilidad del gobierno colonial que entre 1874 y 1878 había intentado silenciar los exponentes más radicales de esa corriente política. Ambos eran notables hombres de letras, ejercían como maestros y se habían visto limitados por las autoridades coloniales en sus intentos de establecer sus propias escuelas. Consistentemente marginados por las autoridades en sus empleos como maestros y hostigados por la censura, emprendieron la propaganda autonomista a comienzos de los 1880. Su origen modesto (Baldorioty era hijo ilegítimo de una mujer de la clase trabajadora y un hacendado del oeste y Marín era hijo de una esclava liberta y un agricultor-comerciante italiano de Arecibo) les permitía constituirse en voz de los grupos medios y artesanales urbanos de origen racial mixto que en los 80 comenzaban a buscar soluciones a su cada vez más deteriorada condición social y económica. ${ }^{23}$

Francisco Gonzalo Marín, periodista y poeta, fue un ferviente admirador de Baldorioty, a quien dedicó una de sus colecciones de poemas. Su obra constituye una expresión aguda de la rebeldía y el resentimiento del grupo criollo ante el régimen político que les marginaba. El joven poeta fue un activo agitador a favor del autonomismo; la crónica local le atribuye haber sido organizador de la sociedad secreta para el boicot contra los comerciantes peninsulares de Arecibo, su pueblo natal. ${ }^{24} \mathrm{Si}$ milarmente, José Celso Barbosa, admirador convencido de las instituciones republicanas, juró lealtad a una de las sociedades secretas del boicot

23 Gautier Dapena: Baldorioty apóstol, San Juan, 1970; Cruz Monclova, Lidio: Baldorioty de Castro..; Coll y Toste, Cayetano: Puertorriqueños ilustres, Barcelona, 1963; "Apéndice para el estudio sobre el origen etnológico del campesinado de Puerto Rico y cruzamiento de raza blanca, india y negra" en Boletín Histórico de Puerto Rico, XI, pág. 259.

24 Cadilla, Francisco: Los ochocentistas, Barcelona, 1961; Coll y Toste, Puertorriqueños ilustres. 
contra los comerciantes peninsulares en 1887, el mismo día de la Asamblea de Ponce, en una reunión secreta a la que fue conducido en Ponce poco antes de marchar de regreso a San Juan. ${ }^{25}$

La táctica del boicot pareció a los más radicales autonomistas la mejor forma de atacar las bases mismas del régimen político. De esta forma erosionaban el poder económico de las mayores casas comerciales de la isla cuyos socios pertenecían al partido conservador (o Incondicional Español) y cuyo rol en lo económico era base de su hegemonía política. Las redes de prestaciones comerciales y financiamiento agrícola de los grandes almacenes peninsulares penetraban cascos urbanos y barrios rurales, lo que les permitía ejercer su influencia y establecer una efectiva maquinaria política. ${ }^{26}$

Existía también un contingente comercial nativo de mediana escala, dueños de tiendas al detall e importadores independientes, en el casco urbano, que intentaba beneficiarse del criollismo radical de los intelectuales para luchar por su supervivencia económica frente a los grandes almacenistas. La devaluación monetaria ponía en dificultades al grupo de importadores independientes de los cascos urbanos al devaluar sus medios de pago en el exterior. Carecían de capital para financiar empresas cafetaleras, negocio que en esos años organizaban eficientemente las redes del gran comercio peninsular. No tener acceso a un valioso fruto de exportación en una coyuntura de devaluación acelerada era sinónimo de ruina económica. La evidencia sugiere, por otro lado, que las casas mercantiles peninsulares tendían a excluir a los criollos en la constitución de sus redes de penetración al interior cafetalero, pues preferían emplear al inmigrante de origen peninsular. ${ }^{27}$

La propuesta criollista no contemplaba un cambio sustancial del sistema económico, sino más bien una sustitución de lo extranjero. Los caficultores eran el blanco preferido de la propaganda de los miembros de las sociedades secretas del boicot contra el comercio peninsular. Los comerciantes criollos de los centros urbanos instaban a los caficultores a que no negociasen con los almacenistas peninsulares que no empleaban

25 Barbosa de Rosario, De Baldorioty a Barbosa..., pág. 116.

26 Ver Cubano, A.: "La política de la élite mercantil y el establecimiento del régimen autonómico en Puerto Rico, 1890-1898" Op.cit. Boletín del Centro de Investigaciones Históricas, 3 (1987-88) pág. 155.

27 Cubano, A.: "El estudio de las élites económicas y la política en Puerto Rico en el siglo XIX”. Ibídem, 4, 1988-1989, pág. 129. 
criollos. ${ }^{28}$ Pero todo parece indicar que los comerciantes nativos y líderes radicales tuvieron dificultades para mantener la lealtad de los caficultores al reclamado apoyo patriótico hacia lo nativo, posiblemente porque las grandes casas comerciales peninsulares ofrecían mejores condiciones de crédito y suministro. Consecuentemente, la táctica del boicot de 1887 no prosperó, aunque hay testimonios que indican que las sociedades secretas con ese fin subsistieron por algunos años. En su contra operó, en primer lugar, la persecución de las autoridades coloniales en 1887, que fue implacable y seguramente logró atemorizar a muchos participantes. ${ }^{29}$ En segundo lugar, muchos líderes autonomistas, empezando por Rafael María de Labra desde Madrid, rechazaron el boicot por considerar que hería el prestigio del autonomismo y le perjudicaba en sus relaciones con el gobierno. Por último está el factor decisivo, que fue el escaso apoyo que recibió el boicot entre los dueños de fincas de café.

Los hombres de letras y comerciantes nativos que organizaron el boicot encontraron seguidores entre los campesinos y los jornaleros del campo, quienes tal vez fueron responsables de la aplicación de las prácticas más violentas como los incendios de establecimientos comerciales de peninsulares. ${ }^{30}$ Esta intervención popular, a la vez que fortalecía el movimiento autonomista dotándole de una base social amplia, le imprimía un carácter tan radical, que provocaba el giro de algunos líderes autonomistas hacia posturas más conservadoras. Muchos intelectuales de origen criollo advertían así los peligros de aliarse a sectores difíciles de controlar y la necesidad de proporcionar bases ideológicas conservadoras e integradoras de una nación puertorriqueña. Irónicamente, la feroz represión del gobierno colonial en 1887, al incurrir en arrestos de autonomistas de clase propietaria lo mismo que de campesinos, con interrogatorios mediante tortura, y en el encarcelamiento de los más destacados dirigentes sospechosos por su orientación radical, sirvió a estos propósitos. Dejó un recuerdo indeleble que a largo plazo serviría para consolidar alianzas de tipo nacionalista entre políticos autonomistas moderados y sectores populares en contra del autoritarismo de la administración colonial española.

28 Ibídem., pág. 132.

29 Ver Cruz Monclova, Historia del año de 1887...; Pedreira, El año terrible del 87...

30 Podría también argumentarse que los campesinos en 1887 reaccionaron espontáneamente contra la dominación de los comerciantes peninsulares, y sin relación alguna con los "grupos políticos de los sectores hegemónicos", como lo hace Fernando Picó: 1898. La guerra después de la guerra, Río Piedras, 1987, pág. 37. 


\section{Los plantadores azucareros frente a la creciente presión fiscal}

En 1886, en vísperas de las alteraciones al orden público de 1887 a que alude la sección anterior, los plantadores azucareros estaban sometidos a una mayor presión fiscal. Para escapar de ésta, es decir, por razones poco ideológicas y muy distantes de las ideas liberales que inspiraban a muchos de sus correligionarios, optaron por una alianza autonomista con grupos medios y populares. El Estado colonial modernizaba su estructura tributaria y amenazaba con derribar una serie de privilegios fiscales que habían logrado los plantadores. El sistema fundamentado en las irregularidades hacendísticas y encabezado por los representantes del negocio azucarero, con la aquiescencia de la administración, se acercaba a su fin en la década de 1880 .

Una de las bases del equilibrio y de la estabilidad política en la colonia había sido, anteriormente, el acceso al poder local que detentaban los hacendados azucareros. La distribución del poder, hasta donde éste era ejercido por los habitantes de la colonia, había favorecido a los más ricos municipios costeros que eran sede de los magnates del azúcar, es decir de los más grandes contribuyentes al Tesoro insular. ${ }^{31}$ Los hacendados azucareros, casi invariablemente habían dominado las instituciones de gobierno local y, por tanto, habían podido manejar a favor de los terratenientes los asuntos relativos a la cuota contributiva que les asignaba el Estado, particularmente en lo concerniente a sumas declaradas de producción imponible, o al cobro de atrasos.

Un estudio de la Intendencia sobre la producción azucarera, ingeniosamente basado en el examen de los gastos de cultivo declarados por los agricultores - lo que seguramente inflaba las cifras de producción, ya que se declaraban con el fin de obtener una exención contributiva-, reveló que el sistema vigente de recaudación dejaba oculta más de la mitad de la riqueza agrícola de Puerto Rico. ${ }^{32} \mathrm{La}$ ocultación fue confesada por los Ayuntamientos, en la opinión del funcionario de $\mathrm{Ha}$ cienda, al negarse éstos a ser visitados por una comisión investigadora para hacer válidas ante la Intendencia sus protestas por la nueva cuota más alta que se les imponía.

31 Cruz. Monclova, Lidio: Historia de Puerto Rico (siglo XIX), v. I,... ofrece varios ejemplos de los mecanismos de consulta y otros mecanismos administrativos que otorgaban poder limitado a los grandes contribuyentes de la isla.

32 La siguiente sección se basa en Archivo Histórico Nacional, Madrid, Ultramar, 1182, exp. 3, 1879-1880. 
En su afán por precisar la verdadera riqueza productiva de la isla, el funcionario de Hacienda se fijó específicamente en los municipios cañeros y encontró graves inconsistencias. Municipios como Ponce, Guayama, Arecibo, Manatí y Carolina, al declarar una productividad de 31-38 quintales de caña por cuerda, quedaban en evidencia al contrastarse con los 50-60 quintales de otras llanuras vecinas como Peñuelas, Juana Díaz, Vega Baja y Trujillo Alto, que aparentemente declaraban más cercano a lo verosímil.

En general, el informe de la Intendencia confirmó las ocultaciones sospechadas al contrastarse la recaudación por contribución territorial con los valores y cantidades exportadas. La inconsistencia era patente. En vez del 5\%, gravamen que supuestamente pesaba sobre la riqueza agrícola en calidad de contribución territorial, Hacienda recaudaba sólo el $1.86 \%$ ya que la imposición se hacía de acuerdo a la riqueza que declaraban los municipios.

Al realizar reajustes en la cuota contributiva para evitar las ocultaciones, la administración central arremetía contra un ámbito de acción tradicionalmente en manos de los gobiernos municipales, que en el litoral eran el centro de operaciones de la élite azucarera, y así cerraba lo que aparentemente había sido una importante válvula de escape al control gubernamental e, indirectamente, una subvención estatal al sector azucarero.

Además de intentar frenar las evasiones, la Intendencia exigió en 1881 la puesta al día por parte de los ayuntamientos en materia de contribuciones agrícolas atrasadas. Varios municipios cañeros habían dejado acumular desde la década de 1860 importantes sumas en calidad de deudas a la hacienda pública. En Arecibo, en 1883, tuvieron que afrontar la presión del gobierno un prestigioso hacendado, Gabriel Correa, que entonces era alcalde, junto a Ruperto Muro, peninsular socio de una firma comercial propietaria de haciendas azucareras (G. Ledesma y Co.) y Manuel Zeno, miembro de familia también propietaria de vegas cañeras, como tenientes de alcalde. ${ }^{33}$

En Ponce el incidente adquirió proporciones mucho mayores. Ante el apremio de la Intendencia por el pago de contribuciones atrasadas desde 1869 , los concejales de esa ciudad se negaron a efectuar los cobros correspondientes a los deudores y rehusaron considerarse ellos mismos

33 Archivo General de Puerto Rico, Fondo de la Diputación Provincial, Arecibo, 7 de agosto de 1883 , doc. 162 . 
responsables del débito. Tras varias peticiones, concesiones de prórrogas sucesivas y amenazas de aplicar medidas coercitivas de la administración central entre 1881 y 1886, las relaciones de la Intendencia con el Ayuntamiento de Ponce se habían tornado bastante tensas. Sólo se había notificado a 32 de los más de 300 responsables del atraso y no se habían embargado bienes a ninguno. El cobro de la deuda, finalmente, requería el embargo de bienes a 96 deudores, lo que significaba la ejecución de "las fincas más valiosas y productivas". ${ }^{34} \mathrm{La}$ Intendencia se enfrentaba con importantes propietarios ponceños. Uno de los que encabezó esta lucha, Ermelindo Salazar, poco después figurará entre los fundadores del Partido Autonomista en la Asamblea de Ponce. Salazar resistió tenazmente las presiones del gobierno central con la queja de que se intentaba llevar a la completa ruina a la jurisdicción municipal ponceña. Otras municipalidades, como Peñuelas y Humacao, habían estado sometidas a la misma persecución fiscal de la Intendencia. ${ }^{35}$ En Mayagüez los hacendados igualmente se resistían a obedecer a la nueva administración de la hacienda pública e iniciaban demandas de revisión de la cuota contributiva para ajustarla a la baja en la producción azucarera de su municipalidad. Sus ingresos netos apenas compensaban la inversión de capital en tierras, maquinarias y edificios. ${ }^{36}$

Los conflictos resultantes del proceso de revisión fiscal que alteró el equilibrio tradicional forjado durante los años del alza en la producción azucarera ponían de relieve ante muchos hacendados las desventajas de su escaso acceso al poder a nivel insular y les impulsaban a colocar sus esperanzas en una nueva administración autónoma de corte criollista que entendían como más moldeable a sus específicas necesidades.

La Diputación Provincial, el organismo más representativo de la estructura administrativa colonial, también se mostraba sorda ante las quejas de los hacendados azucareros. A mediados de la década de 1880 las exportaciones de café comenzaban a mostrar valores tan importantes como las de azúcar, y, al menos desde la perspectiva de la mayoría de los terratenientes de la isla, no había razones para otorgar protección especial a los más grandes capitalistas de la colonia. Las decisiones de la Diputación Provincial se apelaban al gobierno de Madrid. En Arecibo, por

34 Archivo Histórico Nacional, Madrid, Ultramar, 1185, exp. 1, 1886-1887.

35 Ibidem., exp. 2 y 9.

36 Ibidem. exp. 8. 
ejemplo, el hacendado alemán Edmund Pavenstedt, después de fracasar en sus reclamaciones ante la Diputación, llevó su caso al Consejo de Estado en Madrid, donde el líder autonomista Rafael María de Labra era su abogado y representante. Los más reconocidos pilares del régimen español en Puerto Rico, como el hacendado Fernando Fernández o la familia Tejada-Ortiz, propietarios de importantes haciendas en Arecibo, igualmente elevaban sus quejas a la Diputación y luego acudían a Madrid a pedir alivio a la dureza fiscal de los 80. ${ }^{37}$

El negocio del azúcar se había hecho tan comprometido que los comerciantes y los hacendados buscaron nuevas formas de inversión, aunque ninguna aparecía tan rentable. A la vez, trataron de controlar sus costes de producción. Pero aquellos plantadores que, por sus elevadas inversiones recientes, se hallaban obligados a mantener un alto volumen de producción, no tenían opción alguna. La situación les llevó a explorar las posibilidades de una nueva administración autónoma. Los peninsulares, aunque estuvieron sometidos a una presión fiscal similar, no podían entregarse a semejantes especulaciones. A pesar de tener buenas razones para adoptar las tendencias centrífugas de los mayores contribuyentes criollos, los hacendados azucareros de origen peninsular se mantuvieron firmemente en su militancia dentro del Partido Incondicional. Resultaba imposible la creación de un frente unido entre los grupos más poderosos del mundo azucarero.

\section{Conclusiones}

El criollismo tenía bases sólidas. Tenía argumentos convincentes en lo relativo al exceso de empleados públicos, muchos de los cuales por ser de origen peninsular eran especialmente vulnerables a las denuncias de los criollos que les describían como una inservible carga sobre el presupuesto. El gasto militar era excesivo, tratándose de una colonia pacífica como Puerto Rico, y podía explicarse sólo como resultado de actitudes paranoicas de peninsulares que querían controlar la vida colonial. ${ }^{38}$ Los

37 Archivo General de Puerto Rico, Fondo de la Diputación Provincial, Arecibo, 1885-86, "Recurso de agravios que interpone ante este centro Fernando Fernández Umpierre con motivo de la renta imponible a haciendas..", caja 5; Archivo General de Puerto Rico, Fondo de Protocolos Notariales, Arecibo, Notario José A. de la Torre, 3 de febrero de 1887, fol. 220; Archivo Histórico Nacional, Madrid, Ultramar, 1182, exp. 15, 1889.

38 Domínguez, La autonomía administrativa..., pág. 44; Mejías, Félix: Apuntes para la historia económica de Puerto Rico, Río Piedras, 1974, pág. 71. 
autonomistas estaban dispuestos a imponer "economías y todas las simplificaciones" que se juzgasen convenientes en las oficinas de gobierno. ${ }^{39}$ La esperanza de los plantadores era que esos ahorros permitiesen crear una partida del presupuesto colonial destinada al fomento azucarero.

$\mathrm{Si}$ atendemos el problema desde el lado de la élite azucarera, nada nos permite concluir que una administración nativa en un régimen autónomo era, para los grupos más dinámicos de la economía azucarera, equivalente a la obtención de la política económica ideal. El peso de otros sectores agrarios era tal que existía la posibilidad de que fuesen abrumados por la mayoría propietaria de la isla en las discusiones sobre política económica en unas cámaras insulares autonómas. El azúcar era la base de los intereses de un número de propietarios cada vez menor.

El amplio sector caficultor, que, precisamente en esos años, ascendía al primer lugar por los valores de exportación, mantenía una actitud pasiva que, si no confirma, al menos alimenta la sospecha de un apoyo silencioso al régimen español. No se trata de minimizar la hostilidad que provocó un régimen altamente militarizado y dispuesto a ejercer cuanta represión fuese necesaria para mantener un aparente consenso españolista, como quedó demostrado en las persecuciones de 1887 a los autonomistas. Pero el miedo a lo que no dejaba de ser una reducida élite económica peninsular radicada en la isla y una minoría militar opresiva, carente de respaldo metropolitano (como demostró la inmediata destitución de Romualdo Palacio, gobernador responsable de la represión de 1887), me parece insuficiente para explicar la pasividad de un contingente agricultor en su propio territorio y que, a nivel individual, (como demuestra la literatura de la época) era capaz de manifestar un alto grado de fuerza expresiva e incluso violencia física. No deja de ser fructífera, por tanto, la hipótesis de una indiferencia consciente por el proyecto autonomista de 1887 y un apoyo pasivo al régimen vigente.

De esta forma, el escaso apoyo que la población agricultora daba al autonomismo en las elecciones sólo en parte tendría que explicarse a base del fraude y la coerción por parte de los conservadores. Los dirigentes criollos que asumían la dirección de un movimiento para una administración más eficiente y barata, sencillamente no lograban interesar al grueso de los caficultores. Probablemente, la desconfianza de estos crecía con la evidente relación estrecha que mantenían muchos autonomistas con co-

39 Domínguez, La autonomía administrativa..., págs. 10 y 24. 
nocidos plantadores azucareros. Esa unión amenazaba con entronizar a una oligarquía azucarera en un momento en que la fe en el azúcar como base de la economía colonial estaba seriamente quebrantada.

Por su parte, en 1886-1887 los hacendados azucareros no veían más alternativa (salvo la secreta esperanza de que Puerto Rico fuese cedido por España a los Estados Unidos) que acoplarse a esa incómoda alianza, ya con grupos radicales librecambistas y republicanos, ya con aspirantes al empleo público de orientación más moderada, críticos de la corrupción y el autoritarismo en la administración colonial, pero que no siempre compartían su mismo orden de prioridades en materia de política económica. ${ }^{40}$ No parece posible, pues, afirmar que los plantadores eran la principal base social del Partido Autonomista. Esta agrupación se vio cada vez más convertida en un partido de orientación monárquica, de aspirantes criollos al ejercicio público dispuestos a diseñar un presupuesto más a tono con las necesidades de la población criolla, que muy bien podían ser las de la mayoría caficultora. En 1891 los conservadores de la colonia elogiaban los cambios que estaban ocurriendo en el Partido Autonomista, específicamente su abandono del tono exaltado de años anteriores. ${ }^{41}$

El republicanismo urbano, lo mismo que los grupos dispuestos a emplear tácticas radicales como las del boicot, pasaron a ser facciones relativamente débiles. Baldorioty de Castro abandonó la vida política poco después de la fundación del Partido Autonomista. Murió en 1889 decepcionado por el giro conservador que estaban dando sus correligionarios al credo autonomista y republicano que había propulsado. ${ }^{42}$

Tras la muerte de Baldorioty, el apoyo artesanal se hizo titubeante. Los grupos populares urbanos, los más articulados de la clase trabajadora, manifestaban completa independencia de criterio con relación a la política partidista de la clase propietaria. En 1890, el recién fundado periódico El obrero de Ponce lo expresaba en la forma siguiente:

"Ha llegado el momento de que la clase artesana, de que el pueblo llamado con razón soberano tenga también su baluarte donde se estrellen las maquinaciones de los propios y extraños, que siempre le quieren tener subyugado.

40 Para la campaña de los intelectuales autonomistas contra la corrupción, ver Negrón Portillo, El autonomismo puertorriqueño.., págs. 24-25.

41 Boletín Mercantil, 22 de julio y 11 de noviembre de 1891.

42 Cruz Monclova, Baldorioty..., págs. 377-380; para el republicanismo de Baldorioty ver Barbosa de Rosario, De Baldorioty a Barbosa... pág. 59. 
Los que gemían con la cadena del esclavo hasta 1873 nada tienen que agradecer a los nuevos capataces, pues ven a cada paso que sus aspiraciones no son otras que convertirse en modernos mandarines y vivir de la explotación política". ${ }^{43}$

Quedaba claro que el discurso autonomista criollo no penetraba fácilmente en la clase trabajadora, sino que los "propios", o criollos, despertaban sospechas. Aunque el viejo Partido Liberal de la década de 1870 se había ganado la confianza de la clase trabajadora del litoral, gracias primordialmente a la campaña abolicionista, a los nuevos líderes autonomistas se les tenía por "nuevos capataces", y las reivindicaciones criollas del empleo público eran pura ambición y deseo de vivir de las rentas del Estado. El ideal integrador de "la gran familia puertorriqueña", que Quintero Rivera ha identificado acertadamente como lema de los hacendados en su reto a la dominación colonial, parece haber tenido por el momento un alcance demasiado precario. ${ }^{44}$

Tampoco pudo el movimiento autonomista, hasta 1896, encontrar una base electoral amplia entre los caficultores. Los precios del café continuaron en ascenso. Además, la economía cafetalera beneficiaba a otros sectores interdependientes, como el transporte local y la producción para el consumo interno. Era capaz de absorber el costo de una administración colonial que, por lo demás, indirectamente garantizaba la venta de aproximadamente dos terceras partes de la cosecha de café que se exportaban a España y a Cuba. ${ }^{45}$ Por el momento, los autonomistas criollos no pudieron más que refugiarse en una política de retraimiento. La coyuntura favorable para obtener apoyo mayoritario no se presentará hasta la primera baja de los precios del café en el mercado internacional a fines de 1896. Al año siguiente, cuando el gobierno español concede la Carta Autonómica, la victoria electoral de los autonomistas, ya convertidos al monarquismo y fusionados al Partido Liberal de España, estaba asegurada. El segundo brote de política radical surge precisamente en esta coyuntura. El republicanismo de 1897, que cuenta entre sus líderes a José Celso Barbosa, rescatará las propuestas liberales de ultranza de 1886 y dará pie a una considerable agitación de sectores populares urbanos que se prolongará hasta $1904 .{ }^{46}$

43 Ibídem., 22 de junio de 1890.

44 Quintero Rivera, Conflictos de clase..., pág. 24.

45 Para el tema del café ver Bergad, Laird W.: Coffee and the Growth of Agrarian Capitalism in Nineteenth-Century Puerto Rico, Princeton, 1983.

46 Negrón Portillo, Mariano: Las turbas republicanas, 1900-1904, Río Piedras, 1990. 